\title{
FREQUENCY AND SEVERITY OF DEPRESSION IN PRIMARY CAREGIVERS OF PSYCHOTIC PATIENTS.
}

\footnotetext{
1. Doctor of Physical Therapy (DPT) Masters in Orthopedics Manual Physical Therapy (MSOMPT), Lecturer NCS University.

2. MBBS, FCPS (Psychiatry) Assistant Professor Department of Psychiatry Jinnah Medical College Peshawar.

3. MBBS, FCPS (Psychiatry)

Assistant Professor

Department of Psychiatry at $\mathrm{CMH}$ Medical College Lahore.
}

Correspondence Address:

Dr. Shehla Gul

NCS University.

gul_1390@yahoo.com

Article received on: 13/08/2018

Accepted for publication:

14/03/2019

Received after proof reading:

$30 / 09 / 2019$

\begin{abstract}
Shehla Gul ${ }^{1}$, Muhammad Adnan Bashir ${ }^{2}$, Sohail Ali $^{3}$
ABSTRACT... Objectives: The study aimed at determining the frequency and severity of depression in primary caregivers of psychotic patients. Study Design: Cross sectional study. Setting: Out-patient as well as in-patient setting of Department of Psychiatry, Military Hospital Rawalpindi. Period: Six months, from 20 $0^{\text {th }}$ April 2017 to 19th October 2017. Material and Methods: Purposive, non-probable sampling technique was used. A total of 246 caregivers of the same number of psychotic patients were studied after consent, using the General Health Questionnaire 28 (GHQ-28) and Beck's Depression Inventory (BDI). The mean total BDI scores were calculated and correlated with the socio-demographic variables. Results: The mean total GHQ-28 score of 246 caregivers was 7.32 (cut off score is $>7$ ) which indicate definite psychopathology among them. Out of 246 caregivers, $175(71.1 \%)$ showed scores greater than 7 (GHQ positive) while 71 (28.9\%) showed scores less than 7 (GHQ negative). The mean total BDI score of 175 caregivers (who were GHQ positive) was 17.83 (cut off score for depression is $>9)$. Out of $175 \mathrm{GHQ}$ positive caregivers, $72(41.14 \%)$ showed subclinical or no depression, 49 (28\%) showed mild depression, 40 (22.86\%) showed moderate depression and $14(8 \%)$ showed severe depression on BDI. The results show that there is considerable caregiver burden in relatives of psychotic patients. Conclusion: Caregivers of psychotic patients suffer clinical depression with obvious negative outcomes for the patient. Younger age group, female gender and illiteracy typically carry a greater risk of experiencing higher burden in terms of depression.
\end{abstract}

Key words: $\quad$ Care Givers, Depression, Psychotic Patient.

Article Citation: Gul S, Bashir MA, Ali S. Frequency and severity of depression in primary caregivers of psychotic patients. Professional Med J 2019; 26(10):17761782. DOI: 10.29309/TPMJ/2019.26.10.4140

\section{INTRODUCTION}

Care giving is a very common theme all over the world and is typically associated with chronic illnesses or disabilities. Caring for caregivers, however, is a relatively newer concept and has not been studied extensively. In past, psychiatric patients were isolated from society in large custodial institutions. During the second half of the $20^{\text {th }}$ century, a paradigm shift took place in the form of deinstitutionalization in psychiatry and now relatives have become the most important caregivers for adults with major psychiatric disorders. Little work has been carried out regarding experiences and emotional burden on care givers with respect to major mood disorders. ${ }^{1}$ According to latest figures, almost $1 / 3^{\text {rd }}$ to $2 / 3^{\text {rd }}$ of persons with long term psychiatric morbidities currently reside with their family and the family members are significantly affected by their care giving duty. ${ }^{2}$ Mental illness is not a personal failure but once diagnosed, it has a considerable number of devastating consequences, both for the patient as well as for the family. ${ }^{3}$ The term family burden or caregiver burden refers to the effects of the chronic, debilitating illness of one family member on the physical and emotional well-being of other family members as well as on the family members' use of time, general living condition and finances. Everybody providing care to mentally ill does not necessarily experience the negative feelings that meet the criteria of depression. Negative feelings and emotions that come and go over time are perfectly normal but when these negative feelings and emotions are unrelenting then the concerns about depression should arise and it should be screened. ${ }^{4}$ Caregivers of patients with a psychiatric illness have rates of depressive symptoms and clinical 
depression far in excess of those for age matched comparison subjects and the risk persisted even after the care giving ended with the death of the care recipient. ${ }^{5}$ Some of the major factors that influence the caregiver burden and caregiver's psychological well-being have been identified by some recent studies. In one such study incorporating areas of burden and concern of caregivers, the most frequently identified burden was 'worrying about the future' while 'dealing with sadness and grief' was the greatest concern that needed to be addressed. ${ }^{6}$ Psychiatric morbidity and quality of life were affected by caregivers' awareness about the illness and religious as well as cultural beliefs about the cause of illness. ${ }^{7}$ If the patient was unemployed, younger, had poor social functioning and longer duration of illness, a more negative appraisal about care giving prevailed in first degree relatives. ${ }^{8}$

Little work has been carried out to study different aspects of care giver burden in Pakistan and limited data is available that does not fully encompasses the emotional burden of caregivers of psychotic patients presenting in psychiatric health facility. Timely identification and evaluation of the emotional burden faced by caregivers and their subsequent management would help in reducing their sufferings as well as their societal and economic costs.

\section{MATERIALS AND METHODS}

This Cross-sectional study was conducted in outpatient as well as in-patient setting of Department of Psychiatry, Military Hospital Rawalpindi in a period of six months, from20th April 2017 to 19th October 2017.

\section{Sample Size}

As the prevalence of depression in primary caregivers is $20 \%{ }^{9}$, so choosing formula $n=z^{2} p q /$ $e^{2}$, where ' $p$ ' is prevalence (20\%) and ' $e$ ' is standard error (5\%), a sample size of 246 was taken into account through Purposive, Nonprobable sampling technique.

A total number of 246 patients diagnosed with psychosis (Schizophrenia, Delusional Disorder, Schizoaffective Disorder) according to the ICD-10 diagnostic criteria were selected to identify their primary caregivers. Permission was taken from the hospital committee and the primary caregivers accompanying psychotic patients were identified and included into the study after written informed consent. The demographic data of the full sample participating in the research was entered in a structured Performa. The confounding variables were taken care of by detailed history taking, about any current or previous surgical or medical illness, any current or previous evidence of substance/drug use known to produce any psychiatric illness (including depression) prior to the care giving process. Those caregivers with confounding variables were not included in the study, right from the very beginning. General Health Questionnaire 28 (GHQ-28), was applied to all primary caregivers for screening of any psychiatric illness at start. This was followed by application of psychometric rating instrument by the researcher which was Beck's Depression Inventory (BDI) upon those caregivers who scored more than 7 on GHQ-28(caseness/GHQ28 positive) and findings were recorded for each caregiver on structured Performa. The instruments (GHQ-28 and BDI) were administered and rated by the researcher himself therefore there was no requirement of translation of those instruments.

All the data collected was entered and analyzed using a computer software programme called Statistical Package for Social Sciences (SPSS) version 21. Frequency (\%) was calculated for depression, gender, education, marital status, job status, duration of caregiving and relationship with psychotic patient.

\section{RESULTS}

\section{GHQ-28 AND BDI SCORES}

The mean total GHQ-28 score of 246 caregivers was 7.32. Out of 246 caregivers, 175 (71.1\%) showed scores greater than 7 (GHQ positive) while $71(28.9 \%)$ showed scores less than 7 (GHQ negative). The results show that there is considerable caregiver burden in relatives of psychotic patients.

The mean total BDI score of 175 caregivers was 17.83. The BDI score and degree of severity of 
depression are shown in Table-III.

These results showed that caregiver of psychotic patients had significant levels of depression.

\begin{tabular}{|c|c|c|c|c|}
\hline \multirow{2}{*}{$\begin{array}{c}\text { General Health } \\
\text { Questionnaire- } 28\end{array}$} & \multicolumn{2}{|c|}{$\begin{array}{l}\text { Number of } \\
\text { Caregivers }\end{array}$} & \multicolumn{2}{|c|}{ Mean } \\
\hline & \multicolumn{2}{|c|}{246} & \multicolumn{2}{|c|}{7.32} \\
\hline \multicolumn{5}{|c|}{ Table-I. Mean of total GHQ-28 scores } \\
\hline $\begin{array}{l}\text { General Health } \\
\text { Questionnaire-28 }\end{array}$ & \multicolumn{2}{|c|}{$\begin{array}{l}\text { Number of } \\
\text { Caregivers }\end{array}$} & \multicolumn{2}{|c|}{ Mean } \\
\hline GHQ-28 Negative & \multicolumn{2}{|c|}{71} & \multicolumn{2}{|c|}{3.82} \\
\hline GHQ-28 Positive & \multicolumn{2}{|c|}{175} & \multicolumn{2}{|c|}{10.82} \\
\hline Total & \multicolumn{2}{|c|}{246} & \multicolumn{2}{|c|}{7.32} \\
\hline \multicolumn{5}{|c|}{$\begin{array}{c}\text { Table-II. Mean of total GHQ-28 positive and GHQ-28 } \\
\text { negative scores }\end{array}$} \\
\hline \multicolumn{2}{|c|}{ Total BDI Score } & \multicolumn{2}{|c|}{$\begin{array}{l}\text { Numbers of } \\
\text { Caregivers }\end{array}$} & Mean \\
\hline \multicolumn{2}{|l|}{ Normal (0-9) } & \multicolumn{2}{|c|}{72} & 3.65 \\
\hline \multicolumn{2}{|c|}{ Mild Depression (10-18) } & \multicolumn{2}{|c|}{49} & 11.33 \\
\hline \multicolumn{2}{|c|}{ Moderate Depression (19-29) } & \multicolumn{2}{|c|}{40} & 20.01 \\
\hline \multicolumn{2}{|c|}{ Severe Depression (30-63) } & \multicolumn{2}{|c|}{14} & 36.33 \\
\hline \multicolumn{2}{|l|}{ Total } & \multicolumn{2}{|c|}{175} & 17.83 \\
\hline
\end{tabular}

Table-III. Mean of degree of severity of BDI scale

The mean total BDI scores were correlated with socioeconomic and demographic variables with following results.

\section{AGE}

The ages of the caregivers ranged from the youngest being 18 years to the oldest being 65 years. The caregiver age was divided into five groups as follows:

Group 1 (15 to 24 years), Group 2 (25 to 34 years), Group 3 (35 to 44 years), Group 4 (45 to 54 years) and Group 5 (55 to 65 years). The mean age of the caregivers was 37.75 .

Out of 246 caregivers, 40 (16.3\%) had ages ranging from $15-24$ years, $87(35.4 \%)$ had ages ranging from 25-34 years, 68 (27.6\%) had ages ranging from $35-44$ years, 35 (14.2\%) had ages ranging from $45-54$ years and 16 (6.5\%) had ages ranging from 55-65 years., as illustrated in Figure-1.

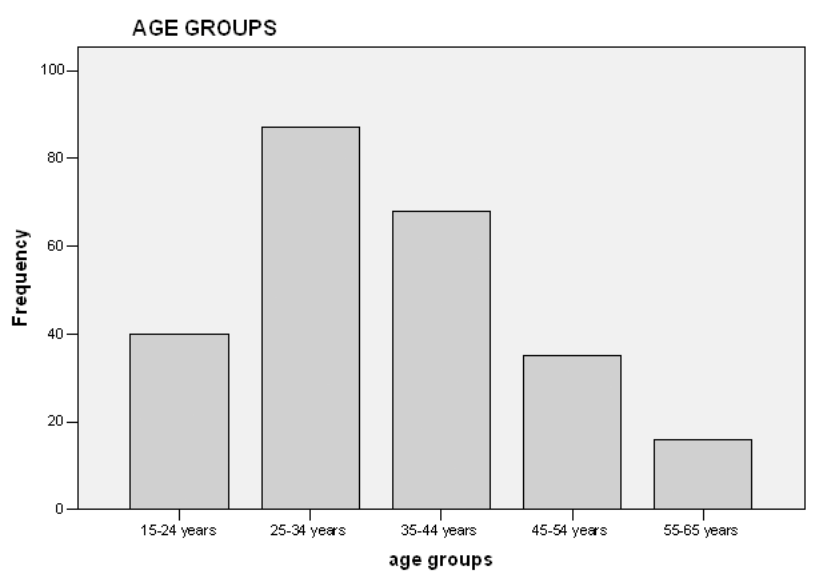

Figure-1. Age wise distribution of caregivers

\section{Gender Distribution of Caregivers}

Out of 246 caregivers, 114 (46.3\%) were males and $132(53.7 \%)$ were females, as illustrated in Figure-2.

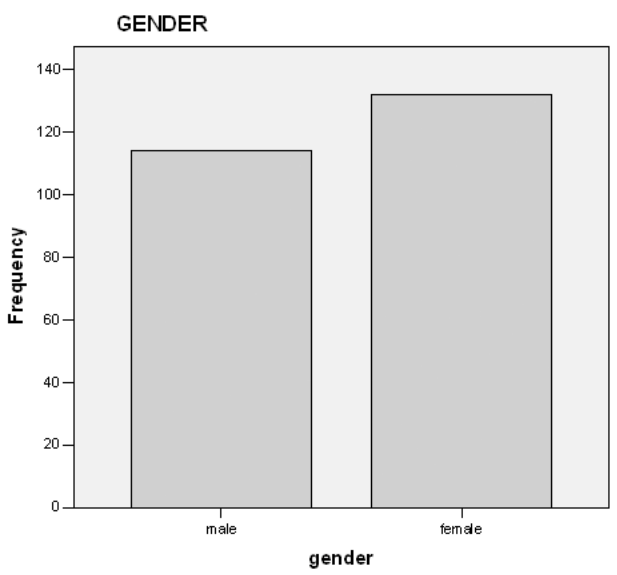

Figure-2. Gender wise distribution of caregivers:

\section{Educational Status}

There was a wide range in the educational status of the caregivers. They were divided into 7 groups on the basis of level of education.

Group 1 (illiterate), Group 2 (primary), Group 3 (middle), Group 4 (matriculate), Group 5 (intermediate), Group 6 (graduate) and Group 7 (post graduate).

Out of 246 caregivers, 42 (17.1\%) were illiterate, $51(20.7 \%)$ were primary passed, $47(19.1 \%)$ were middle passed, 39 (15.9\%) were matriculate, 34 (13.8\%) were intermediate passed, 26 (10.6\%) were graduate and 7 (2.8\%) were post graduates, 
as illustrated in Figure-3.

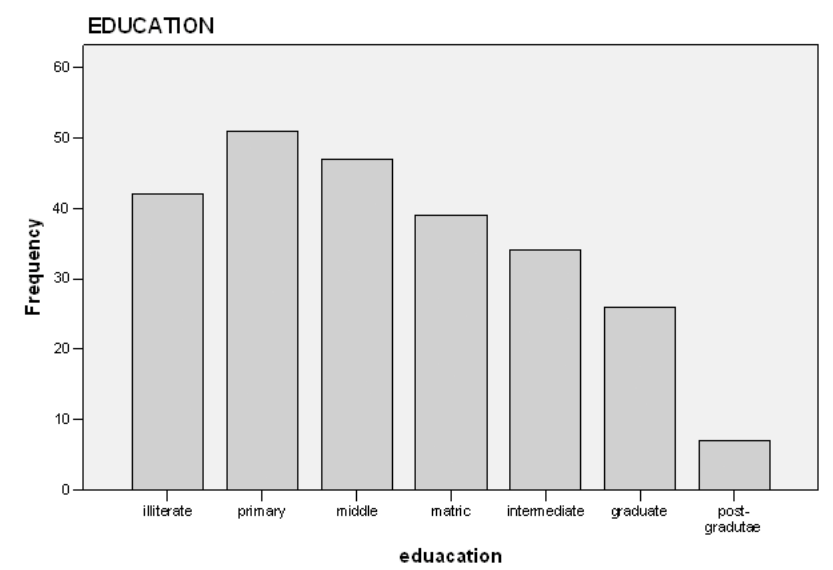

Figure-3. Educational status of caregivers

\section{Marital Status}

Marital status of caregivers was divided into five groups.

Group 1 (single), Group 2 (married), Group 3 (separated), Group 4 (divorced) and Group 5 (widows).

Out of 246 caregivers $37(15 \%)$ were single, 188 (76.4\%) were married, 7 (2.8\%) were separated, 5 (2\%) were divorced and 9 (3.7\%) were widows, as illustrated in Figure-4.

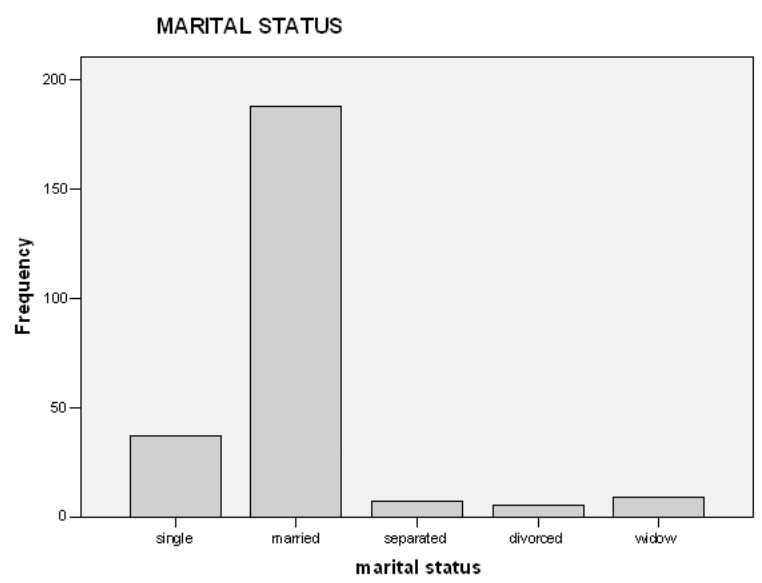

Figure-4. Marital status of caregivers

Job Status

Regarding job status caregivers were divided into two groups:

Group 1 (unemployed) and Group 2 (employed).

Out of 316 caregivers, 115 (46.7\%) were unemployed and 131 (53.3\%) were employed, as illustrated in Figure-5.

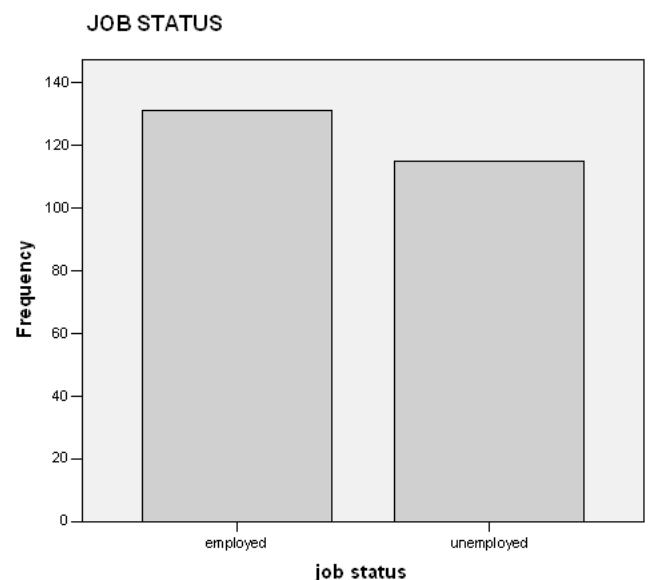

Figure-5. Job status of caregivers

\section{Income Per Month}

The monthly income of caregivers was divided into 5 groups:

Group 1 (<5000 Rs), Group 2 (5000 to 10000 Rs), Group 3 (10000 to 20000 Rs), Group 4 (20000 to 30000 Rs) and Group 5 (>30000 Rs).

The mean of income groups was 2.27 and standard deviation was 1.34.

Out of 246 caregivers, 98 (39.8\%) earned less than 5000 Rs per month, 53 (21.5\%) earned 5000 to 10000 Rs per month, 38 (15.5\%) earned 10000 to 20000 Rs per month, 31 (12.6\%) earned 20000 to 30000 Rs per month and 26 (10.6\%) earned more than 30000 Rs per month, as illustrated in Figure-6.

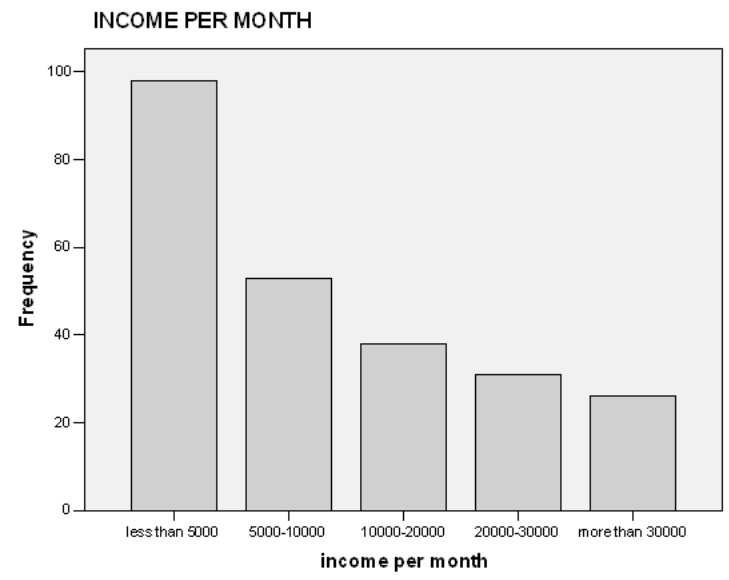

Figure-6. Income per month of caregivers 


\section{Duration of Care Giving}

The duration of care giving was divided into 4 groups as follows:

Group1 ( $<1$ year), Group 2 (1-5 years), Group 3 (5-10 years) and Group 4 ( $>10$ years).

The mean duration of care giving was 1.86 years and standard deviation was 0.92 .

Out of 316 caregivers, 108 (43.9\%) performed care giving role for less than one year, 84 (34.1\%) performed care giving role between 1 to 5 years, $40(16.3 \%)$ performed care giving role between 5 to 10 years and $14(5.7 \%)$ performed care giving role for more than 10 years, as illustrated in Figure-7.

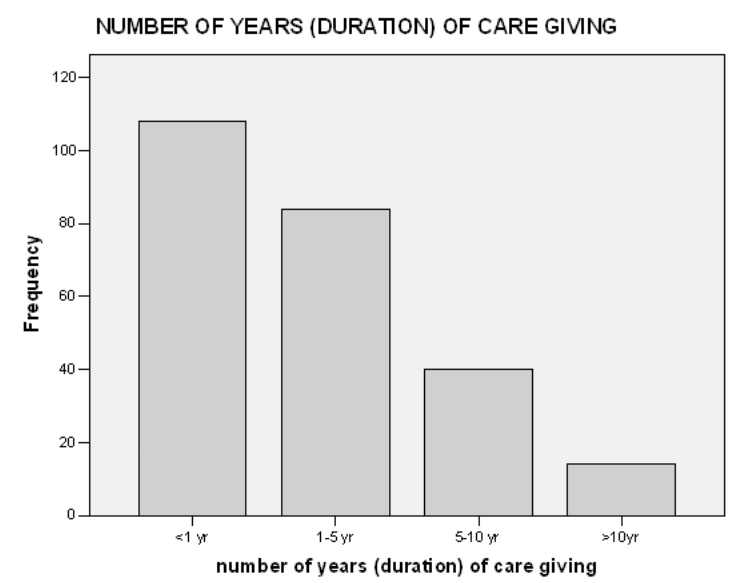

Figure-7. Duration of care giving

\section{Relationship with Patient}

Out of 246 caregivers, 62 (25.2\%) were mothers, $49(19.9 \%)$ were fathers, $52(21.1 \%)$ were wives, $33(13.4 \%)$ were husbands, 16 (6.5\%) were sons, $14(5.7 \%)$ were brothers, 9 (3.7\%) were daughters, $5(2 \%)$ were sisters, $4(1.6 \%)$ were daughters in law and $2(0.8 \%)$ were sons in law, as illustrated in Figure-8.

\section{DISCUSSION}

This study aims at identifying the frequency and severity of depression amongst the caregivers of patients of psychosis. The mean total GHQ-28 score of 246 caregivers was 7.32 (cut off score is $>7$ ) which indicate definite psychopathology among them.

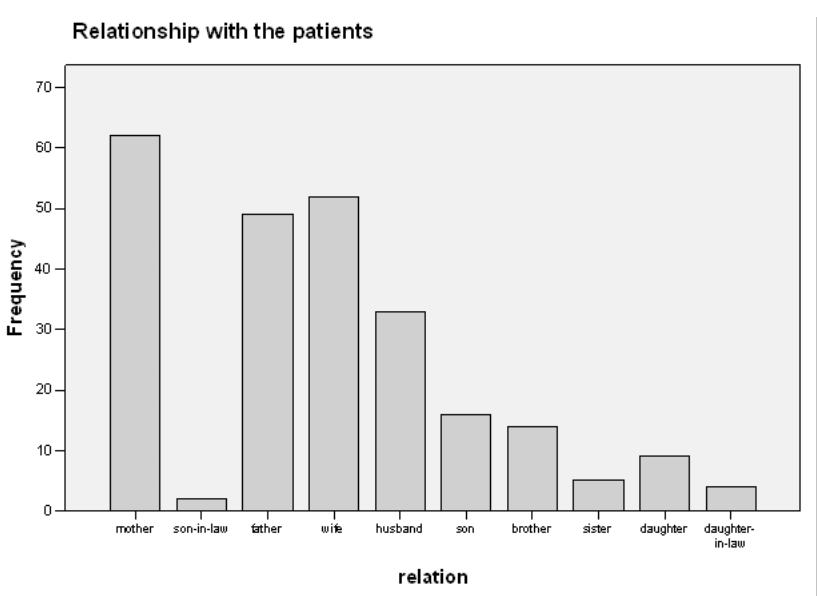

Figure-7. Duration of care giving

Out of 246 caregivers, $175(71.1 \%)$ showed scores greater than 7 (GHQ positive) while 71 (28.9\%) showed scores less than 7 (GHQ negative). The caregiver of psychotic patients showed high scores on depression scales. The mean total BDI score of 175 caregivers (who were GHQ positive) was 17.23 (cut off score for depression is $>9$ ). Out of 175 GHQ Positive caregivers, 72 (41.14\%) showed subclinical or no depression, 49 (28\%) showed mild depression, $40(22.86 \%)$ showed moderate depression and 14 (8\%) showed severe depression on BDI. The results show that there is considerable caregiver burden in relatives of psychotic patients. The illiterates and caregiver wives had the highest mean total BDI scores. Female caregivers and caregivers with lowest monthly income $(<5000 \mathrm{Rs})$ showed higher mean total BDI scores than male and financially stable caregivers. The job status of the caregivers had no effect on caregiver burden as per the results.

The results of this study did commensurate with that of Basheer et al. ${ }^{4}$ The authors found that caregivers of patients with severe depression had significant high level of depression and anxiety; and the burden was higher for female caregivers as compared to male caregivers. They also found that the depression was higher in caregivers who had been recently providing care. A possible explanation may be that in the initial phase of treatment, things are newer for the caregiver and he or she worries not only about the patient but also about the other family members and how to deal with the mental illness 
of the patient. The caregiver burden in terms of depression and variables associated with it, have been studied extensively in numerous studies. Up till now, although most studies agree that caregivers experience burden, yet there has been little agreement about factors influencing that burden. ${ }^{10}$

\section{LIMITATIONS OF STUDY}

1. The most important limitation is the genetic vulnerability, if the caregiver is a relative. Relatives of psychotic patients themselves are at increased risk of developing any psychiatric illness including depression as compared to the general population.

2. Depression is common psychiatric morbidity in general population. The present study is an observational study that indicates the presence of depression in the caregivers of psychotic patients but does not necessarily link depression to their care giving status.

3. The higher suspicion of Information bias could not be ruled out. In Pakistani culture the caregivers may hesitate to declare caregiver burden (shame and guilt).

4. Most of the individuals were from Punjab province and few areas of KPK. So the sample does not represent the entire country, a country with a diverse cultural and belief systems.

5. Other related issues such as caregivers' quality of life, anxiety and global functioning were not taken into account and only depression was studied.

\section{CONCLUSION}

Caregivers of psychotic patients suffer considerable burden. This burden includes significant levels of clinical depression; a negative impact on their psychological and physical health; as well as greater societal and economic cost. This brings into focus an imminent need to develop community based mental health services in the developing countries like Pakistan, by trained caregivers rather than relying on females as caregivers for patients. Caregivers have sufferings which are comparable to the sufferings of physically and mentally ill patients. Timely identification and evaluation of caregivers for psychiatric morbidity, while assessing psychotic patients, may be a useful strategy in reducing their psychological, emotional and burden.

Copyright(C) 14 March, 2019.

\section{REFERENCES}

1. Stam $H$, Cuijpers $P$. Effects of family interventions on burden of relatives of psychiatric patients in the Netherlands: a pilot study. Community Ment Health $\mathrm{J}$ 2001; 37:179-87.

2. Dyck DG, Short R, Vitaliano P. Predictors of burden and infectious IIIness in schizophrenia caregivers. Psychosom Med 1999; 61:411-41.

3. Eriksson M, Svedlund M. 'The intruder': Spouses' narratives about life with a chronically ill partner. $J$ Clin Nurs 2006; 15: 324-33.

4. Basheer S, Niazi RS, Minhas FA, Ali W, Najam N. Depression and anxiety in the caregivers of mentally ill patients. J Pak Psych Society 2005; 2: 27- 33.

5. Mittelman MS, Roth DL, Coon DW, Haley WE. Sustained Benefit of Supportive Intervention for Depressive Symptoms in Caregivers of Patients with Alzheimer's disease. Am J Psychiatry 2004; 161:850-6.

6. Rose LE, Mallinson RK, Gerson LD. Mastery, burden and areas of concern among family caregivers of mentally ill persons. Arch Psychiatr Nurs 2006; 20:4151.

7. Chen PS, Yang YK, Liao YC, Lee YD, Yeh TL, Chen CC. The psychiatric wellbeing and associated factors of caregivers of outpatients with schizophrenia in Taiwan. Psychiatry Clin Neurosci, 2004; 58: 600-5.

8. Ostman M, Hansson L. Appraisal of caregiving, burden and psychological stress in relatives of psychiatric inpatients. Eur psychiatry 2004; 19: 402-7.

9. Hiller W, Zaudig M, Bose MV. The overlap between depression and anxiety on different levels of psychopathology. Journal of Affective Disorders 1989; 16: 223-31.

10. Nehra R, Chakrabarti S, Kulhara P, Sharma R. Caregivercoping in bipolar disorder and schizophrenia: $A$ reexamination. Soc Psychiatry Psychiatr Epidemiol 2005; 40: 329-36. 


\section{AUTHORSHIP AND CONTRIBUTION DECLARATION}

\begin{tabular}{|c|c|c|c|}
\hline Sr. \# & Author-s Full Name & Contribution to the paper & Author's Signature \\
\hline 1 & Shehla Gul & $\begin{array}{l}\text { Introduction, Study design, } \\
\text { Data collection, Data analysis, } \\
\text { Resutls. }\end{array}$ & $A+m a n$ \\
\hline 2 & M. Adnan Bashir & $\begin{array}{l}\text { Discussion, Conclusion, } \\
\text { Abatract Writing }\end{array}$ & Hdenar \\
\hline 3 & Sohail Ali & Data collection. & \\
\hline
\end{tabular}

